\title{
Detection of antimicrobial drug residues in milk marketed at different areas of Sindh province
}

\author{
Abdul Samad Mangsi ${ }^{1}$, Muhammad Khaskheli ${ }^{1}$, Aijaz Hussain Soomro ${ }^{2}$ and \\ Muhammad Ghiasuddin Shah ${ }^{3}$ \\ ${ }^{I}$ Department Of Animal Products Technology, Faculty Of Animal Husbandry \& Veterinary Sciences, Sindh \\ Agriculture University, Tandojam-PAKISTAN \\ ${ }^{2}$ Institute Of Food Sciences And Technology, Faculty Of Crop Production, Sindh Agriculture University, \\ Tandojam-PAKISTAN \\ ${ }^{3}$ Department Of Veterinary Anatomy \& Histology, Faculty Of Animal Husbandry \& Veterinary Sciences, Sindh \\ Agriculture University, Tandojam-PAKISTAN
}

\begin{abstract}
The study was conducted to screen the milk samples for drug residual contamination marketed at the vicinities of Hyderabad, Mirpurkhas, Sukkur, Larkana, and Karachi divisions of Sindh province. Out of total 400 samples, $49.75 \%$ were found positive for antibiotic residues, and over residual positive samples the highest percent was in the vicinity of Karachi followed by Hyderabad, Sukkur, Larkana and Mirpurkhas. The overall mean zone size was measured as $14.27 \pm 0.26 \mathrm{~mm}$ in milk marketed at different areas of Sindh. Milk samples positive to antimicrobial drugs were further screened through Twin Sensor ${ }^{B T}$ KITO20, and found that $\beta$-lactam was highest at Larkana followed by Hyderabad, Karachi, Mirpurkhas and Sukkur. The residual limit of Tetracycline was higher in samples obtained from Hyderabad, relatively similar percent was found in milk samples from Mirpurkhas and Larkana and least in samples of Sukkur. The overall residual contamination in milk was higher (38.29\%) for $\beta$-lactam than that of Tetracycline (21.14\%) group. It could be concluded that indiscriminate pattern or misuse of antibiotics at various stages of milk processing may have shown the significant influence and the residual level in milk reached at the peak point.
\end{abstract}

Keywords: antimicrobial, detection, market milk, residues

\section{Introduction}

In Pakistan milk is the major output of livestock sector; accounts for 5.3\% value addition to GDP, 25.5\% to agriculture and 49\% to livestock. Sindh, the second largest province of Pakistan in terms of population and the third in area is rich in natural resources suitable for livestock including rangelands [1]. Livestock is growing sector in all parts of the province. The "Landhi Cattle Colony" is the world's biggest population of buffaloes/cattle at one place; hence this colony usually referred to cattle colony of Karachi. In colony and its vicinity, more than 2, 50,000 buffaloes and cattle are kept together for milk production [2]. Moreover, the cattle, buffalo, sheep and goat ( 32.945 million heads) reared in different parts of province may provide approximately 10.68 million tons of milk [3]. The province constitutes over 21 percent livestock population and $23 \%$ milk production of the country. Such type of precious commodity is produced from the animals which are always under the shadow of antibiotics that are mainly used by farmers with or without guidance of veterinarians to prevent or treat the diseases and to enhance production. The use of antimicrobial drugs in dairy animals/cows is mostly for the treatment of mastitis. Such widespread usage has created potential residual problems in milk and milk products. Hence enter into the human food chain causing physiological, pharmacological, pathological and toxicological health hazards to the consumers. In addition, they also interfere in the fermentation process of cultured milk products. Protection of public health against possible harmful effects of veterinary drug residues is a relatively recent preoccupation. In order to safeguard the human health, the World Health Organization (WHO) and Food and Agriculture Organization (FAO) have set certain standards for acceptable daily intake and maximum residues limit (MRLs) for each antibiotic in milk. These limits apply to both the parent drugs or chemical and its metabolism that may accumulate and be deposited or stored within the cell, tissues or organs following the administration of the compound.

In Sindh, no any reliable program has been observed for the monitoring of drug residues in milk. Thus the control of residues of antimicrobial drugs in milk producing animals and animal food products has been a cornerstone of the present Agricultural and Food policies to provide assurance to consumers about the safety and wholesomeness of their food. Keeping in view the importance of subject this study was designed to detect the presence of antimicrobial drug residues in raw milk marketed at different areas of Sindh province. 


\subsection{Sample collection:}

\section{Materials and Methods}

The raw milk samples were randomly collected from dairy shops/ sale points / milk vendors at different Divisions/areas (i.e. Hyderabad, Mirpurkhas, Sukkur, Larkana, and Karachi) of Sindh province for screening of antimicrobial drug residues. A total of 400 samples from the vicinities of above said divisions ( 80 from each division) were collected into clean sterile bottle, and transported under refrigeration to the laboratory of the Department of Animal Products Technology for analysis. All the samples were stored under refrigerator till analysis.

\subsection{Detection through microbial inhibitor assay:}

Milk samples were screened for the presence of different antimicrobial residues using Bacillus subtilus Qualitative Field Disc Assay (microbial inhibitor), as described by Association of Official Analytical Chemists (AOAC) [4]. The blank discs of filter papers (Whatman 1, 12mm) were completely dipped into pre-prepared sample and control using forceps, and placed on the surface of agar medium containing the sensitive test organism (Bacillus subtilus). The plates were incubated at $37^{\circ} \mathrm{C}$ for $24 \mathrm{hrs}$. The positive results (the presence of antibiotic residues) were manifested by formation of transparent zones around the disc and compared with control group. The zone size around each positive sample was measured using Vernier caliper. Since no zone was appeared in control samples, the data on the zone size of samples were gathered for comparison purpose.

\subsection{Screening through Twin Sensor ${ }^{\mathrm{BT}}$ method:}

In later stage, amongst the residual positive milk samples, thirty five $(n=35)$ samples from each of five divisions were further screened for $\beta$-lactam (Penicillin and Cephalosporin) and Tetracycline (Chlortetracycline, Doxycycline, Oxytetracyclin and Tetracycline) groups using Twin Sensor ${ }^{\text {BT }}$ (KIT020) method. Milk sample $(200 \mu \mathrm{l})$ was transferred into reagent micro-well and mixed to homogeneity. It was incubated for $3 \mathrm{~min}$ at $40^{\circ} \mathrm{C}$ using water bath (Fisher Scientific Versa-Bath), then Dipstick was dipped into microwell and it was further incubated for $3 \mathrm{~min}$ at similar temperature. Finally the colour intensity of both test lines (upper line for Tetracycline and bottom line for $\beta$-lactam) was compared with the colour intensity of control line (central line) on the Dipstick. The negative result was noted when colour intensity of test line was darker than control line, and the positive when it was lighter than control line.

\section{Results:}

The samples of milk obtained from different divisions/areas of Sindh were examined for the contamination of antimicrobial drugs (Table-1). It has been observed that among the total numbers (80) of milk samples examined at Hyderabad division/area, $41(51.25 \%)$ samples were found as positive. In case of milk samples examined at Mirpurkhas division/area (80), $36(45.00 \%)$ samples were detected as positive. While in the vicinity of Sukkur Division, out of 80 samples of milk 39 (48.75\%) samples found to be positive for residual contamination. Moreover, at Larkana Division 37 (46.25\%) milk samples were found as positive among a total of 80 numbers examined. Whereas, at the Karachi Division, over total numbers (80) of milk samples analyzed, $46(57.50 \%)$ samples observed as positive for antimicrobial residues. Further it was observed that out of total 400 milk samples, 199 (49.75\%) numbers were observed as positive for residual contamination.

Table-1 Distribution of antimicrobial drug residues in samples of milk marketed at different divisions/areas of Sindh Province

\begin{tabular}{|l|l|l|l|l|}
\hline \multirow{2}{*}{ Division/area } & \multicolumn{2}{|c|}{ Number of samples } & \multirow{2}{*}{ Positive \% } \\
\cline { 2 - 4 } & Examined & Positive & Negative & \\
\hline Hyderabad & 80 & 41 & 39 & 51.25 \\
\hline Mirpurkhas & 80 & 36 & 44 & 45.00 \\
\hline Sukkur & 80 & 39 & 41 & 48.75 \\
\hline Larkana & 80 & 37 & 43 & 46.25 \\
\hline Karachi & 80 & 46 & 34 & 57.50 \\
\hline Overall & 400 & 199 & 201 & 49.75 \\
\hline
\end{tabular}

Moreover, the diameters of inhibition zones in positive milk samples were evaluated (Fig. 1). It was noted that mean zone size was significantly high $(\mathrm{P}<0.05)$ in milk samples marketed in the vicinity of Karachi $(18.7 \pm 1.56 \mathrm{~mm})$ followed by Hyderabad $(15.67 \pm 1.33 \mathrm{~mm})$, Larkana $(13 \pm 1.32 \mathrm{~mm})$, Mirpurkhas $(12.5 \pm 1.00 \mathrm{~mm})$ and Sukkur $(11.17 \pm 0.82 \mathrm{~mm})$. Further it was observed that the overall mean zone size was measured as $14.27 \pm 0.26 \mathrm{~mm}$ in milk marketed at different areas of Sindh. 


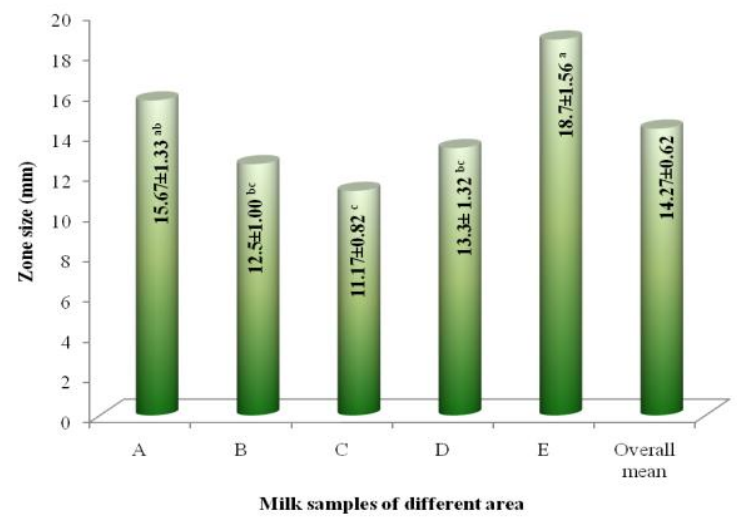

$\operatorname{LSD}(0.05)$

SE \pm

$$
\begin{aligned}
& =3.4763 \\
& =1.7430
\end{aligned}
$$

$\mathrm{A}=$ Hyderabad, $\mathrm{B}=$ Mirpukhas, $\mathrm{C}=$ Sukkur, $\mathrm{D}=$ Larkana, $\quad \mathrm{E}=$ Karachi

Figure-1 Average zone size $(\mathrm{mm})$ of antimicrobial drug residues positive milk samples marketed at different divisions/areas of Sindh Province

Milk samples positive to antimicrobial drugs were further screened through Twin Sensor ${ }^{\mathrm{BT}}$ KIT020 shown in Table-2. It reveals that in the vicinity of Hyderabad division $40.00 \%$ (14 numbers) samples were contaminated with $\beta$-lactam residues and $25.71 \%$ (9 numbers) with Tetracycline group, while $34.29 \%$ (12 numbers) of samples were contaminated with unknown antibacterial drugs/inhibitors. In case of Mirpurkhas division, the $\beta$-lactam, Tetracycline and other /unknown drug residual contamination in milk samples was 37.14, 20.00 and $42.86 \%$, respectively. Whereas at Sukkur division $34.29 \%$ samples were found to be contaminated with $\beta$-lactam antibiotics, $17.14 \%$ with Tetracycline and $48.57 \%$ were contaminated with unknown/other antibiotics. Moreover, at Larkana division majority of samples (42.86\%) were found to be contaminated with $\beta$ lactum, $20.00 \%$ with Tetracycline and $37.14 \%$ with unknown drugs/inhibitors. Milk sample obtained from Karachi division/area were found more $(40.00 \%)$ contaminated with unknown antibacterial/inhibitor residues and the least $(22.16 \%)$ with Tetracycline residues, where $37.14 \%$ of samples were contaminated with $\beta$-lactam residues. The overall residual contamination of $\beta$-lactam in milk samples was observed as $38.29 \%$ (67 numbers) and the Tetracycline $21.14 \%$ (37 numbers), while the residues of unknown antimicrobial drugs /inhibitors was $40.57 \%$ (71 numbers), among total 175 antibiotic positive samples.

Table-2 Number and percent of milk samples positive to B-lactum and Tetracycline residues screened through Twin Sensor ${ }^{B T}$ KIT020 method

\begin{tabular}{|l|c|c|c|c|c|c|c|}
\hline \multirow{2}{*}{ Division } & \multirow{2}{*}{ No. of samples } & \multicolumn{2}{|c|}{$\boldsymbol{\beta}$-lactum } & \multicolumn{2}{c|}{ Tetracycline } & \multicolumn{2}{c|}{$\begin{array}{c}\text { Other /unknown } \\
\text { antibiotics }\end{array}$} \\
\cline { 3 - 8 } & & No. & $(\%)$ & No. & $(\%)$ & No. & $(\%)$ \\
\hline Hyderabad & 35 & 14 & 40.00 & 9 & 25.71 & 12 & 34.29 \\
\hline Mirpurkhas & 35 & 13 & 37.14 & 7 & 20.00 & 15 & 42.86 \\
\hline Sukkur & 35 & 12 & 34.29 & 6 & 17.14 & 17 & 48.57 \\
\hline Larkana & 35 & 15 & 42.86 & 7 & 20.00 & 13 & 37.14 \\
\hline Karachi & 35 & 13 & 37.14 & 8 & 22.86 & 14 & 40.00 \\
\hline Overall & 175 & 67 & 38.29 & 37 & 21.14 & 71 & 40.57 \\
\hline
\end{tabular}

\section{Discussion}

Milk and milk products contaminated with antibiotics beyond a given levels, are considered unfit for human consumption [5]. It has been reported that several active veterinary drugs are commercially available and at least seventy five of these are being used more or less extensively in dairy animals for therapeutic and prophylactic purposes [6]. Nevertheless, more than 80 veterinary drugs are likely residues in animal-derived food as identified by USA Food and Drug Administration (FDA) [7], and excessive or improper use of these drugs is of a great concern about the presence of residues in food of animal origin. No doubt, the use of veterinary drugs in food animal species is strictly regulated by the countries in the European Union, and in fact only some of them are permitted for specific therapeutic purposes under strict control and administration by a veterinarian [8]. However, countries where rules on the use of veterinary drugs are silent, the residues of these substances or their metabolites in milk may cause adverse effects on consumers' health. Therefore, in the present study milk samples were collected from dairy shops, sale points or milk vendors at the vicinities of Hyderabad, Mirpurkhas, Sukkur, Larkana, and Karachi divisions to examine the antibiotic residues, it was 
observed that among the total 400 samples of milk, $49.75 \%$ were found to be positive for antibiotic residues. Result of present study is not in line with the study conducted by Arora and Chhabra [9] who found only $23.80 \%$ positive samples for antibacterial residues from a total of 45 milk samples, whilst $38.9 \%$ positive samples over 72 screened milk samples were recorded by Ahmad et al. [10]. The high incidence of antibiotic residues in milk samples collected under current study is in agreement with Taj-Elsir [11], who reported that high percentage of antimicrobial residues in raw milk collected from vendors might be due to use of antibiotics as preservatives to increase the shelf life of raw milk. It could be argued that over residual positive samples of milk (199 numbers) observed in the present study, the highest percent (57.50) was observed in the vicinity of Karachi followed by Hyderabad (51.25\%), Sukkur (48.75\%), Larkana, (46.25\%) and Mirpurkhas (45.00\%). It is of interest to note that higher level of incidence of antibiotic residues might be due to adulteration by addition of antibiotic to the milk in order to prolong its shelf life as milk is supplied to Karachi very far from it. However, this trend of residual contamination may pose more potential health threats to consumers residing at Karachi and the least at Mirpurkhas. Moreover, it has been reported that variation in residual contamination in milk varied place to place, for example, out of the cow milk samples with penicillin G residues, 5\% (19/384) originated from Masaka district, while 8\% (31/384) originated from Mbarara district [12]. Similarly Ahmad et al. [10] detected the antibiotic residues in $28(38.90 \%)$ of examined milk samples, $17(23.60 \%)$ of these were in Khartoum North and 11 (15.30\%) were in Khartoum. In current study the average diameter of inhibition zones in positive milk samples was remarkably $(\mathrm{P}<0.05)$ high in milk samples of karachi followed by Hyderabad, larkana, Mirpurkhas and Sukkur and the overall mean zone size was measured as $14.27 \pm 0.26 \mathrm{~mm}$ in milk marketed at different areas of Sindh. These findings were in the range of results as reported by Jevinova et al. [13] who found a wide range ( 2 to $20 \mathrm{~mm}$ ) of diameter of inhibition zones in milk determined using microbiological assays. They further indicated that higher inhibition on the medium might be due to the amount of natural inhibitors (lysozyme, lactoferrin etc) in milk.

In current study further results through Twin Sensor ${ }^{\mathrm{BT}}$ KIT020 reveal that $\beta$-lactam was highest at Larkana Division (42.86\%) followed by Hyderabad (40.00\%), Karachi (37.14\%), Mirpurkhas $(37.14 \%)$ and Sukkur (34.29\%). The residual limit $\mathrm{f}$ or Tetracycline was higher in milk samples obtained from Hyderabad (25.71\%) and least in Sukkur (17.14\%), relatively similar percent (i.e. 20.00) was found in milk samples obtained from Mirpurkhas and Larkana. The residues of unknown drugs were higher in milk samples obtained from Sukkur (48.57\%) followed by Mirpurkhas, Karachi, Larkana and Hyderabad (42.86, 40.00, 37.14, 34.29\%, respectively). The overall residual contamination in milk was highest for unknown drugs $(40.57 \%)$ and the lowest for Tetracycline (21.14\%), while the residues of $\beta$-lactam were screened as $38.29 \%$. However, Schmidt and Rodrick [14] reported that in most of the countries, the most frequently detected antibiotics are $\beta$-lactam antibiotics while tetracycline only in rare cases. Whilst Sasanya et al. [12] detected residues of penicillin G above the levels of European Union stipulated maximum drug limit of $4 \mu \mathrm{g} / \mathrm{l}$ from 13\% (50/384) of cow milk over total samples (384) analyzed using the Charm Farm® Test. Khaskheli et al. [15] detected 36.50\% residues of B-lactam antibiotics over 137 unprocessed market milk samples collected from Hyderabad city, Latifabad and Qasimabad using microbial screening test (Bacillus subtilus Field Disc Assay) and High Performance Liquid Chromatography (HPLC) methods. They further reported that the level of residues of Penicillin G (mean $59.53 \mu \mathrm{g} / \mathrm{L}$ ) in unprocessed milk was 14.9 and 11.9 fold, Amoxicillin (mean $36.11 \mu \mathrm{g} / \mathrm{L}$ ) 9.03 and 3.61 fold,

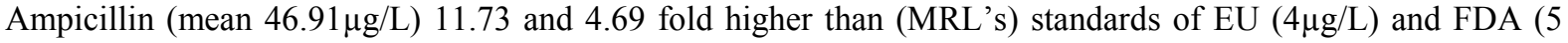
and $10 \mu \mathrm{g} / \mathrm{L})$, respectively.

\section{Conclusions}

It could be concluded that the livestock/dairy farms, sale points and milk vendor shops were found to be under indiscriminate or misuse of antibiotics. Milk marketed at Karachi division was seems to be more contaminated with antibacterial residues compared to that of at other divisions (Larkana, Sukkur, Hyderabad and Mirpurkhas) of Sindh province under present study. Withdrawal period of antibiotics were seems to be not followed by milk producers. This study suggested that the regulatory authorities should ensure proper withdrawal period before milking the animals and definite supervisions are necessary on application of these drugs. The authorities should also adopt comprehensive strategy for ensuring a safe milk supply of good quality.

\section{VI- Acknowledgements}

This research work has been carried out as part of the Project [NO.PSF/ NSLP/S-SAU (64)] funded by Pakistan Science Foundation, Islamabad.

\section{References}

[1]. F. M. Mari, Status and constraints of livestock production in Sindh province of Pakistan, International Journal of Advanced Rural Management, 1(1), 2013, 1-10. 
[2]. M. Q. Bilal, M. Suleman, and A. Raziq, Buffalo: black gold of Pakistan. Livestock Research for Rural Development, 18 (9), 2006 , 128.

[3]. [O. Farooq, Agriculture, In: Pakistan economic survey 2012-13 (Economic advisor's wing, Finance division, Government of Pakistan, Islamabad, 2013).

[4]. AOAC, $\beta$-Lactam Antibiotics in milk (Bacillus subtilis Qualitative Field Disk Assay), in Officials Method of Analysis, Association of Official Analytical Chemists, (International, Gaithersburg, Maryland, USA, 2000).

[5]. J. E. Hillerton, B. I. Halley, P. Neaves, and M. D. Rose, Detection of antimicrobial substances in individual cow and quarter milk samples using Delvotest microbial inhibitor tests, Journal of Dairy Science, 82, 1999, 704-711.

[6]. M. M. L. Aerts, A. C. Hogenboom, and U. A. T. Brinkman, Analytical strategies for the screening of veterinary drugs and their residues in edible products, Journal of Chromatography B, 667, 1995, 1-40.

[7]. S. Ghidini, E. Zanardi, G. Varisco, and R. Chizzolini, Prevalence of molecules of ß-Lactam antibiotics in bovine milk in lombardia and Emilia Romagna (Italy), Ann. Fac. Med. Vet. Di Pharma, 22, 2002. 245 - 252

[8]. M. Reig, and F. Toldra, Veterinary drug residues. Handbook of processed meats and poultry analysis, (Taylor \& Francis Group, LLC, New York, USA, 2009) 647-666.

[9]. A. Arora, and D. Chhabra, 2004, Screening for antimicrobial residues in milk by disc assay. Indian Veterinary Journal 81 (12), $1400-1401$.

[10]. M. M. A. S. Ahmad, E. M. I. El-Zubeir, A.O. O. El-Owni, and A. M. K. Ahamed, Assessment of microbial loads and antibiotic residues in milk supply in Khartoum State Sudan. Research Journal of Dairy Sciences, 2(3), 2008, 57-62.

[11]. S. Taj-Elsir, Antibiotic residues in raw cow milk at Khartoum State, M.Sc Thesis, University of Khartou, Sudan, 2001.

[12]. J. J. Sasanya, F. Ejobi, J. Enyaru, D. Olila, and G. Ssengoye, Public health perspectives of Penicillin G residues in cow milk and edible bovine tissues collected from Mbarara and Masaka Districts, Uganda, Africa Journal of Animal and Biomedical Sciences, 3 (2), 2008, 35-40.

[13]. P. Jevinova, E. Dudrikova, J. Sokol, J. Nagy, and D. Mate, Determination of oxytetracycline residues in milk with the use of HPLC method and two microbial inhibition assays, Bulletin of the Veterinary Institute in Pulawy, 47, 2003, 211-216.

[14]. R. H. Schmidt, and G. E. Rodrick, Food safety, (Hand book, John Wiley and Sons, New Jersey, 2003) 312-313.

[15]. M. Khaskheli, R. S. Malik, M. A. Arain, A. H. Soomro, and H. H. Arain, Detection of $\beta$-Lactam antibiotic residues in market milk. Pakistan Journal of Nutrition, 7 (5), 2008, 682-685. 